\title{
DROUGHT IMPACTS ON VEGETATION ACTIVITY IN THE MEDITERRANEAN REGION: AN ASSESSMENT USING REMOTE SENSING DATA AND MULTI- SCALE DROUGHT INDICATORS
}

\author{
C. Gouveia' ${ }^{1}$, R.M. Trigo ${ }^{1}$, S. Beguería ${ }^{2}$ and S.M. Vicente-Serrano ${ }^{3}$ \\ [1]\{Instituto Dom Luís, Faculdade de Ciências da Universidade de Lisboa, Campo Grande \\ Edifício C8, Piso 3, 1749-016 Lisboa, Portugal\} \\ [2]\{Estación Experimental de Aula Dei, CSIC, Zaragoza, Spain \} \\ [3] \{nstituto Pirenaico de Ecología, CSIC, Zaragoza, Spain $\}$
}

This manuscript is submitted to the special issue of Global and Planetary Change entitled: “Climate Variability and Change in the Mediterranean Region" (SI: Mediterranean climate)

Co-Editors: Piero Lionello, Emin Ozsoy, Serge Planton, Giovanni Zanchetta

$\begin{array}{ll}\text { Correspondence to: } & \text { Célia Gouveia (cmgouveia@fc.ul.pt) } \\ & \text { Instituto Dom Luiz } \\ & \text { Faculdade de Ciências da Universidade de Lisboa } \\ & \text { Campo Grande, Edifício C8, Piso 3, Sala 8.3.03 } \\ & \text { 1749-016 Lisbon } \\ & \text { Portugal }\end{array}$




\section{Abstract}

The present work analyzes the drought impacts on vegetation over the entire Mediterranean basin, with the purpose of determining the vegetation communities, regions and seasons at which vegetation is driven by drought. Our approach is based on the use of remote sensing data and a multi-scalar drought index. Correlation maps between fields of monthly Normalized Difference Vegetation Index (NDVI) and the Standardized PrecipitationEvapotranspiration Index (SPEI) at different time scales (1-24 months) were computed for representative months of winter (Feb), spring (May), summer (Aug) and fall (Nov). Results for the period from 1982-2006 show large areas highly controlled by drought, although presenting high spatial and seasonal differences, with a maximum influence in August and a minimum in February. The highest correlation values are observed in February for 3 months' time scale and in May for 6 and 12 months. The higher control of drought on vegetation in February and May is obtained mainly over the drier vegetation communities (Mediterranean Dry and Desertic) at shorter time scales (3 to 9 months). Additionally, in February the impact of drought on vegetation is lower for Temperate Oceanic and Continental vegetation types and takes place at longer time scales (18-24). The dependence of drought time-scale response with water balance, as obtained through a simple difference between precipitation and reference evapotranspiration, varies with vegetation communities. During February and November low water balance values correspond to shorter time scales over dry vegetation communities, whereas high water balance values implies longer time scales over Temperate Oceanic and Continental areas. The strong control of drought on vegetation observed for Mediterranean Dry and Desertic vegetation types located over areas with high negative values of water balance emphasizes the need for an early warning drought system covering the entire Mediterranean basin. We are confident that these results will provide a useful tool for drought management plans and play a relevant role in mitigating the impact of drought episodes. 


\section{Introduction}

Climatic droughts are relatively frequent in the Mediterranean region as a consequence of the large interannual variability of precipitation (Lionello, 2012), and long periods with low precipitation (Lloyd-Hughes and Saunders, 2002). Several studies have emphasized the spatial and temporal complexity of droughts in this region (e.g. Van der Schrier et al. 2006, Sousa et al. 2011; Vicente-Serrano et al., 2012a). Also a number of recent studies identified a significant increase in the frequency of drought events in the Mediterranean basin (Sousa et al., 2011; Hoerling et al., 2012; Vicente-Serrano et al., 2014). Significantly, some of these studies include state-of-the-art models confirming that this drying trend is driven, at least partially, by increasing amounts of greenhouse gases (Hoerling et al., 2012; Trigo et al., 2013). This overall evolution fits well into an expected tendency towards more frequent dry periods in a future warmer climate (Giorgi and Lionello, 2008; IPCC, 2012). In the Mediterranean region, large drought episodes are responsible for the most negative impacts on vegetation. Among other impacts, Mediterranean droughts often imply substantial losses of crop yield (Austin et al., 1998; Rodríguez-Puebla et al., 2007; Schillinger et al., 2008), increasing risk of forest fires (Pausas, 2004; Pellizzaro et al., 2007), and even forest decline (Martínez-Villalta et al., 2008; Limousin et al., 2008; Camarero et al., 2014). Additionally, significant drying trends are known to prompt land degradation processes in arid and semiarid regions (e.g., Nicholson et al., 1998; Pickup, 1998), that may also affect vulnerable and low resilient vegetation communities in the Mediterranean (Vicente-Serrano et al., 2012a).

The strong dependence of vegetation dynamics on water availability has been for long recognized in the Mediterranean region (Undelhoven et al., 2009; Gouveia et al., 2009; Gouveia et al., 2012, Vicente-Serrano, 2007; Lindner et al., 2010). Given the high frequency 
of droughts, the Mediterranean vegetation is well adapted to drought events using different morphological and phenological strategies (Braun-Blanquet and Bolós, 1954). Nevertheless, the Mediterranean landscape has been modified during centuries by humans (Puigdefábregas and Mendizábal, 1998), affecting the present dominant vegetation communities and, subsequently, both the capacity of resistance and resilience of the natural vegetation to droughts (Alados et al., 2011). Vicente-Serrano et al. (2012a) showed that vegetation degradation could be enhanced by the enlarged aridity resulting from lower precipitation and higher atmospheric evaporative demand. In this context, the risk of drought-related damages on the vegetation cover has increased significantly during the last decades in the Mediterranean region (Peñuelas et al., 2001; Jump et al., 2006; Camarero et al., 2014). Therefore, it constitutes a high priority to further evaluate the influence of droughts on the dynamics of the Mediterranean vegetation. The majority of the studies about drought impacts on the vegetation cover considered droughts as a precipitation shortage regarding the normal climatology. Nevertheless, large evapotranspiration rates associated to high temperatures are equally relevant and may reinforce drought severity. The last decade was characterised by large heatwaves affecting western (2003) central (2007) and eastern (2010) sectors of the Mediterranean and Europe (Trigo et al., 2005, Amraoui et al. 2013; Barriopedro et al., 2010). During the summer 2003 a large increase of temperature in central and western Europe noticeably strengthened the severity of the drought conditions and caused large impact on vegetation activity and crops (e.g., Lobo and Maisongrande, 2006; Coret et al., 2004; GarciaHerrera et al., 2010). Both the 2003 Western Europe and 2010 Russia Mega-heatwave episodes led to marked decreases in plant productivity, with less carbon uptake by vegetation (Bastos et al., 2014). In the case of the 2003 heatwave, moisture deficits coupled with high temperatures steered the extreme response of vegetation (Ciais et al., 2005), while for the 2010 event extremely high temperatures seem to be the main driver of very low productivity 
(Bastos et al., 2014). In southwestern Europe, a higher atmospheric evaporative demand has increased drought severity, leading to a decrease in surface water resources (Trigo et al., 2013; Vicente-Serrano et al., 2014). Therefore, in the present scenario of temperature increase not only it is necessary to acknowledge the impacts of the reduction in precipitation but also to consider droughts as water stress conditions, caused as a consequence of both precipitation shortages and high atmospheric evaporative demand.

To determine the impact of droughts on Mediterranean vegetation is difficult given strong landscape diversity, with vegetation species having different resistance to drought (Maherali et al., 2004). Topographical, climatic and edaphic factors but also the land use history introduce much more complexity to the analysis. Moreover, a number of drought characteristics, such as drought severity, seasonality and prevailing time-scales can be relevant to assess drought impacts in different vegetation types (Vicente-Serrano et al., 2013). In semi-arid regions of northeast Spain, Vicente-Serrano (2007) and Pasho et al. (2012) showed large differences in the vegetation response to drought at different time scales. At the global scale, differences in the vegetation response to drought time-scales are also important (Vicente-Serrano et al., 2013).

The use of remote sensing data holds a great potential since it allows analyzing large regions. The availability of longer satellite time series, covering the entire globe, such as the GIMMS dataset, has allowed the analysis of the relationships between climate variability on vegetation dynamics and crop yields both at global or continental scales (Lobell and Field, 2007, Gouveia et al, 2008, Zeng et al, 2013). Different studies for the Mediterranean analyzed the impact of droughts on the natural vegetation and crops using remote sensing data, including Lloret et al. (2007) and Vicente-Serrano (2007) in Northeast Spain, Lobo and Maisongrande (2006) in France, Gouveia (2009 and 2012) in Portugal, Dorman et al. (2013), 
Trigo et al. (2010) in the eastern Mediteranean area, Paz-Kagan et al., (2014) in Israel, Ezzine et al. (2014) in Morocco, and Ivits et al (2013) in Europe, among others. There are no studies, to the best of our knowledge, covering the entire Mediterranean basin for more than 25 years, focusing at the vegetation community level, with the purpose of determining the vulnerability of the dominant vegetation types to climate droughts. Additionally, no previous studies have considered the combined effect of precipitation and the atmospheric evaporative demand on drought severity but also the use of different drought time-scales.

The aim of the present work is to analyze the drought impacts on vegetation in the entire Mediterranean region using remote sensing data, with the purpose of determining the most sensitive vegetation communities and the drought-time scales more prone to cause negative effects on vegetation.

\section{Data and Methods}

\subsection{Study area and vegetation indices}

We have defined the Mediterranean region as roughly spanning the area between $10^{\circ} \mathrm{W}$ $-40^{\circ} \mathrm{E}$ and $20^{\circ} \mathrm{N}-50^{\circ} \mathrm{N}$. Such large area is bound to encompass sharp contrasts in the influence of climatic droughts on vegetation given the climatic and topographical diversity and the varied vegetation communities, soil types and land uses. In order to associate the drought impacts with the main vegetation communities over the whole Mediterranean region we have used the GlobCover dataset. The GlobCover project was an initiative of ESA (European Space Agency) to produce a global land cover map with a resolution three times sharper than what was available from any previous satellite map. The GlobCover project used the high resolution (300 m) mode data from the MEdium Resolution Imaging Spectrometer (MERIS) sensor on-board ENVISAT satellite, acquired throughout the year 2005. The 
GlobCover classification over Mediterranean region was resampled for the GIMMS-NDVI spatial resolution $(8 \mathrm{~km})$ based on the mode rule for degradation of thematic maps (Figure 1).

With the aim of assessment how aridity conditions control the drought impact on vegetation, we have computed a simple climatic water balance (WB) based on the difference between the average annual precipitation and the average Reference Evapotranspiration (ETo), that provides a quantification of the available water scarcity or excess for the different seasons (Figure 2). The Reference Evaporation (ET0) is computed using the Thornthwaite equation that relies only on temperature data. The Penmann-Monteith equation requires several meteorological variables to be calculated (wind speed, solar radiation, relative humidity and temperature) that were not available at the Mediterranean scale. Although the limitations of the intrinsic definition of water balance, related with the obvious differences between ET0 and actual evapotranspiration, together with the non-local effects, such as the high mountains, we opted to use this simple definition, due to the aim of doing an analysis over the entire Mediterranean basin, based on the available climatic gridded time-series. The CRU TS3.2 dataset, compiled and processed by the Climate Research Unit of the University of East Anglia were used to compute WB.

Given the spectral properties of vegetation, which absorbs an important percentage of electromagnetic energy in the visible band and reflects a high percentage in the near-infrared region (Knipling, 1970), vegetation indices can be computed from satellite imagery and used to analyze vegetation dynamics in general (e.g., Myneni et al., 1997), climate/vegetation relationships (e.g., Nemani et al., 2003) and the impacts of droughts in particular (e.g., Kogan, 1997).

Among the existing vegetation indices, the Normalized Difference Vegetation Index (NDVI) (Rousse et al., 1974) is the most widely used to analyze vegetation activity from 
remote sensing data. Numerous authors have pointed out the close relationship between NDVI and several ecological parameters. The NDVI measures the fractional absorbed photosynthetically active radiation (FPAR) (Myneni et al., 1995) and exhibits a strong relationship with vegetation parameters such as green leaf area index (Baret and Guyot 1991, Carlson and Ripley 1997), green biomass (Tucker et al., 1983, Gutman 1991, Cihlar et al., 1991, Diallo et al., 1991), or fractional vegetation cover (Gillies et al., 1997).

The Global Inventory Modeling and Mapping Studies (GIMMS) dataset, with $8 \mathrm{~km}$ of spatial resolution is the most complete and longest remote sensing dataset covering the entire Mediterranean region (Tucker et al., 2005; Pinzon and Tucker, 2014). The GIMMS data set is derived from imagery obtained from the Advanced Very High Resolution Radiometer (AVHRR) instrument onboard the NOAA satellite series 7, 9, 11, 14, 16 and 18. The GIMMS NDVI dataset that has been corrected for calibration, view geometry, volcanic aerosols, and other effects not related to vegetation change (Pinzon and Tucker, 2014). Given its temporal consistency and quality, this dataset has been widely used to analyze vegetation dynamic and climate impacts on vegetation (e.g., Gurgel and Ferreira, 2003; Goetz et al., 2006; Heumann et al., 2007). Here, we transformed the biweekly GIMMS-NDVI images from 1982 to 2006 to monthly composites by means of the Maximum Value Composite method, which merely involves to choose, for each pixel, the date of maximum NDVI within 10 consecutive daily NDVI values (Holben, 1986). The monthly NDVI dataset was then converted in series of standardized anomalies (stNDVI) by means of the average and standard deviation of each grid series. The analysis was restricted in such a way that the area without vegetation (e.g., bare soil) or corresponding to irrigated crops (accordingly to the GlobCover classification) was masked and are represented in gray in the following figures.

With the aim of summarizing main vegetation types over the selected area, based on 
the seasonality of vegetation, a cluster analysis was applied using monthly NDVI averages over the entire period. The cluster analysis was performed based on the $\mathrm{K}$ means technique (MacQueen, 1967; Hartigan and Wong, 1975) that uses an iterative fine-tuning method to minimize the sum of squares of distances between data and the cluster centroid (Gouveia et al., 2009). We performed a sensitivity study on the number of clusters to be retained, which varied between four and eight, having found optimized results when using six clusters (Figure 3, top panel). The six vegetation classes based on the seasonal differences in the NDVI values were named based on classes typical of bioclimatic classifications (Rivas-Martínez et al., 2011) as: Desertic (D), Mediterranean Dry (MD) and Mediterranean Oceanic (MO), Temperate Dry (TD) and Temperate Oceanic (TO) and Temperate Continental (TC). The cluster Desertic presents extremely low values of NDVI (corresponding essentially to bare soil) over the entire year (Figure 3). There is a clear predominance of the vegetation classes with the maximum of vegetation greenness in spring over the Southern Mediterranean countries, Iberia and Turkey, while most of the Northern Mediterranean region is characterized by classes with a maximum in summer months.

\subsection{Drought Index}

We have used the Standardized Precipitation Evapotranspiration Index (SPEI) to quantify drought severity and temporal variability of droughts. The SPEI is based on the climatic balance between precipitation and the atmospheric evaporative demand, and it has a multi-scalar character which is crucial to determine the impacts of droughts on vegetation (Vicente-Serrano et al., 2010; Beguería et al., 2014). The SPEI data was obtained from the SPEI global dataset (Beguería et al., 2010), at time scales between 1 and 48 months and at a spatial resolution of $0.5^{\circ}$. This dataset was derived using the CRU TS3.2 database, compiled and processed by the Climate Research Unit of the University of East Anglia and covers the 
period between 1901 and 2011, coinciding with the GIMMS database during the period 19822006. The SPEI index using time scales between 1 and 24 months were further interpolated to the resolution of the images GIMMS, with the aim of verify the response of vegetation to water deficits of different duration. Details on spatial and temporal assessment of the SPEI dataset can be found at Beguería et al. (2010) and Vicente-Serrano et al. (2010).

\subsection{Statistical analysis}

We performed the correlation analysis between monthly values of NDVI and monthly SPEI for time-scale from 1 to 24 months (12x24=288 correlation maps). Furthermore we have equally evaluated for each season the months showing the highest control of drought (SPEI) on vegetation (NDVI). In order to simplify the unworkable amount of maps produced we opted to focus our analysis on representative months for each season, knowing in advance that this specific chosen month represent the higher control of drought on vegetation. We selected one representative month for each season: February (winter), May (spring), Aug (summer) and Nov (autumn) to determine seasonality effects in the impact of droughts on vegetation (Figure 2). Water scarcity is notable during summer, while higher water availability can be observed in autumn and winter.

With the aim of identifying the vegetation areas and seasons most affected by climatic droughts we computed all the correlation coefficients between monthly anomalies of NDVI in February, May, August and November vs. SPEI at the time scales of 3, 6, 9, 12, 18 and 24 months to consider short, medium and long drought time scales. Correlation maps with the 8 $\mathrm{km}$ of spatial resolution were obtained, and the month and time scale of the drought index that resulted in the highest correlation were retained. The maps representing the maximum correlation obtained at each grid-point for the 6 considered time scales were derived. Hereafter it will be defined the areas affected by drought, as the areas where vegetation is 
affected by variability in hydrological conditions, as obtained through significant positive correlations values. Afterwards, the dependence of drought impacts to water availability was assessed analyzing the relationship of correlation between NDVI and SPEI values and the water balance values for each cluster, time scale and season, by means of scatter plots in the areas with significant correlations.

\section{Results}

\subsection{The simultaneous use of NDVI and SPEI for drought assessment}

The spatial distribution of correlation fields between stNDVI and SPEI is represented in Figure 4. The grid point correlation values are shown for the temporal scales of 3, 6, 9, 12, 18 and 24 months and for representative months of the four seasons: February, May, August and November. During the four seasons, there are noticeable differences between the SPEI and stNDVI correlations considering the different SPEI time-scales. The correlation patterns of stNDVI vs. SPEI have high spatial homogeneity for a wide range of times scales, although they present higher positive and significant correlations $(\mathrm{p}<0.05)$ for the shortest time scales ( 3 and 6 months). It may be noted the higher correlations found for August in almost all the Mediterranean in contrast with February and November where significant values tend to be clustered in smaller regions of western and eastern Mediterranean, respectively. An intermediate situation is found during May, with sub-regions presenting significant correlations, although restricted to Iberia, Northern Africa and Eastern Mediterranean. An important sector of the northwestern African continent, including Morocco, Algeria and Tunisia present the most consistent results of positive correlation values between stNDVI and SPEI throughout the different seasons and covering a wide range of the time scales considered. Likewise, the correlation patterns also present high positive correlations over 
Iberia in February and over Balkan Peninsula during November for both time scales.

In order to identify the strongest stNDVI/SPEI relationship in each season, we have selected that corresponding to the time scales showing the highest correlation (Figure 5). This figure presents the spatial distributions of monthly composites of significant correlations $(\mathrm{p}<0.05)$ for the stNDVI/SPEI, independently of the time-scale and relative to February (upper left panel), May (upper right panel), August (bottom left panel) and November (bottom right panel). Table 1 presents the total amount of significant correlations obtained for each season and time scale. The amount of vegetated area with statistically significant correlation values changes significantly at the seasonal scale, with a maximum in August (with 39907 pixels with significant correlations that corresponds to $35.6 \%$ of the vegetated area) and a minimum in February (8910 pixels corresponding to 5.6\% of vegetated area) and May and November presenting intermediate values (2163 and 14172 corresponding respectively to $17.4 \%$ and $13.1 \%$ of the area with vegetation).

\subsection{Drought impacts on vegetation at different time scales}

The spatial distributions of the time-scale showing maximum correlation at each gridpoint for all six considered SPEI time-scales are shown in Figure 6, for February (upper left panel), May (upper right panel), August (bottom left panel) and November (bottom right panel).

The relative proportions of the SPEI time-scale that showed the maximum correlation in the areas with significant correlations between the SPEI and the stNDVI during February, May, August and November are showed in Figure 7. Around 20\% of the area showing a significant correlation corresponds to the longer time scales (18 and 24 months) and this proportion persists fairly constant along the year, with a relative minimum in May (Figure 7). 
Nevertheless the amount of affected area for the time scale of 12 (9) months is higher in November (May) and lower in February (November). It should be noted the increase from winter to autumn of the areas more affected by the SPEI at short time-scales (3 months).

The highest positive correlations ( 0.70) spread over the majority of the Mediterranean during August including northwestern Iberia, France, north of Italy and west and north of Black Sea (Figure 5, left bottom panel). Around one third of this area corresponds to the 3 month time scale (Figure 7). In May the high correlation values are restricted to northern Africa, southern Iberia and the eastern Mediterranean (Figure 6), that corresponds essentially to $75 \%$ of the affected area (Figure7). The vegetation is affected by drought in May at different time scales including 3 months (southeastern Iberia, area around Gibraltar and eastern Mediterranean) and 6 and 12 months (southwestern Iberia and Northern Africa) (Figure 6, right upper panel). In November the most affected areas are located north and west of the Black sea while during February these are confined to north of Africa (Figure 6, bottom right panel) with around $40 \%$ of the significantly affected area associated to the shortest time scale. Finally the higher influence of drought on vegetation in February is restricted to northwestern Africa and Iberian sectors (Figure 6, upper left panel) being dominated by the 6 month time scale, represent almost $55 \%$ of the affected area.

Figure 8 presents the boxplots of time scales for the area affected by drought on a seasonal and annual basis (bottom panel) corresponding to different time scales. Table 1 presents the number of pixels presenting significant correlation from each time scale and season, as well as the number the percentage of outliers presented in Figure 8. The suspect outliers are defined as those that are at least $1.5^{*}$ Interquartile Range greater than the upper quartile or $1.5^{*}$ Interquartile Range less than the lower quartile. In general, they are equal or less than $2.5 \%$ of the pixels with significant correlations. The exceptions are found in 
February for the time scales of 12 and 24 months (respectively with 3.6 and 3.4\%) (Table 1). The large number of pixels included in the analysis together with the lower percentage of outliers presented highlights the robustness of our analysis. From analysis of the SPEI timescales at which the maximum SPEI-NDVI correlations are recorded, we found that vegetation activity in February responds predominantly to short drought time-scales (from 6 to 9 months) although presenting a wide range of values. The correlation values are lower for higher time scales, although with a smaller spread. During May and August the correlation coefficients present large amplitude of values with higher median values for 6 and 12 months in May. During November the range of values is lower for all time scales. However when the analysis is performed at the annual basis (bottom panel), i.e. merging the significant values obtained for Feb, May, Aug and Nov, the spread observed for the different times scales is similar despite the higher median values for 6 and 9 time scales.

\subsection{Drought impacts over different vegetation communities}

In this section we analyze the vegetation types more prone to drought events and the dominant time-scales at which drought influences vegetation by means of the nexus through the evaluation of SPEI-NDVI correlation values for different vegetation types at both the seasonal and annual basis (Figure 9). Table 2 presents the number of pixels presenting significant correlation from each cluster and season, as well as the number the percentage of outliers presented in Figure 9. Once again the large number of pixels included in the analysis together with the lower percentage of outliers presented highlights the robustness of our analysis. In general, the number of outliers is equal or less than $2.5 \%$ of the pixels with significant correlations, being the exceptions observed in February for Temperate Oceanic (TO) and Temperate Continental (TC) with respectively 3.8 and $4.6 \%$ of the amount of 
significant correlations observed in the vegetation communities. While the higher correlation values in February and May were obtained for Mediterranean Dry and Desertic clusters, the lowest median values were obtained for Temperate Oceanic (TO) and Mediterranean Oceanic (MO) clusters. The Mediterranean Oceanic cluster presents also low correlation values during August and November whereas the other clusters present similar median values. It should be noted that, in general, clusters with higher median values also present the largest range of values. The analysis at annual basis (bottom panel) summarizes the above mentioned control of drought on vegetation types, with higher correlation values for Mediterranean Dry (MD) and Arid clusters whereas the Temperate Oceanic clusters presents slightly lower correlation values.

The dominant time-scales at which drought influence the different vegetation communities is presented in Figure 10. The median values at which vegetation responds to drought over the Temperate Oceanic cluster corresponds to shorter time scales ( 3 months) in August and larger in November (12 months), presenting intermediate values during February and May. However the spread is lower in May and August and higher in February. The vegetation over the Mediterranean Oceanic (MO) cluster responds to drought at short median time scale values for February and May (with very low spread) and at 12 months in November although with very large spread of time scales. In the case of Mediterranean Dry cluster the spread of time scales increases significantly from February to November while the median values remain fairly constant around 6 months for all seasons. On the other hand the dominant times scales at which vegetation is driven by drought over Mediterranean Oceanic cluster present the largest median values in February (18 months) and values between 9 and 12 months for the other months, with all seasons characterized by high spread. The vegetation over the Desertic cluster responds to drought at the larger time scales (24 months) in February, decreasing in the other months with a minimum in November (6 months). Finally 
the Desertic cluster responds to drought at shorter time scales (between 3 months in November and 12 months in August). When evaluating on an annual basis (bottom panel) the larger median values and spread of time scales are observed over the Mediterranean Oceanic cluster.

\subsection{The influence of water availability conditions}

The relationship between the water balance (WB) and the correlation is displayed in Figure 11 for different vegetation clusters (panel a) and time scales (panel b). The values of the pairs SPEI-NDVI correlation values versus WB averaged over vegetation clusters and time scales are associated to positive (negative) WB values for autumn and winter (spring and summer). The best relationship considering the vegetation clusters was obtained for February and May $\left(\mathrm{R}^{2}=0.81\right.$ and $\mathrm{R}^{2}=0.66$ respectively) presenting the Mediterranean Dry, Desertic and Mediterranean Oceanic clusters the higher SPEI-NDVI correlation values for lower values of WB (positive values in February and negative values in May). The best relationship considering the time scales was obtained for February $(\mathrm{R} 2=0.90)$ presenting the shorter time scales (3, 6 and 9) the higher correlation values for dryer areas (lower WB values). It should be noted the tendency for a change of the slope representing the dependence of the correlation values with WB; the dependence is negative for cold and wet seasons and tend to be positive for hot and dry seasons (although through non-significant regression adjustment in these cases). Usually the wet and moist clusters are associated with high values of WB (less negative in summer and spring and more positive in autumn and winter) (Figure 11, panel a).

Taking into account the results obtained in the upper and lower panels of Figure 11 one can expect that the time scales of the affected area may be also related with the average annual WB. This analysis is provided in Figure 12 where the best relationship is obtained for 
February and November $\left(\mathrm{R}^{2}=0.65\right.$ and $\mathrm{R}^{2}=0.90$, respectively). The line of regression representing the dependence of the time scales with WB is negative in summer and positive in the other seasons. The lower WB values are associated to the Mediterranean Dry, Desertic and Mediterranean Oceanic clusters in all seasons, moreover whereas in summer they correspond to higher time scales, during the other seasons they are associated with lower time scales.

\section{Discussion and Conclusions}

The Mediterranean region has been identified as one of the areas where climate change scenarios are most consistent confirming the hotspot status of the area (Giorgi, 2006; Gao and Giorgi, 2008). The high risk for an increase water stress on crops and natural ecosystems and the consequent risk of land degradation and desertification is notorious over the southern sectors of Europe, the Mediterranean, Middle East and northern Africa (Gao and Giorgi, 2008; Hoerling et al., 2012). In recent years a relative large number of studies focused on droughts in the Mediterranean basin have been published driven by the occurrence of major drought events or by the prospect of increasing drought scenarios for the region. Here we have adopted a comprehensive methodology to analyze the drought impacts on vegetation that can be considered innovative in the following aspects: i) the use of long time series (including 25 years of remote sensing data, ii) the analysis of the entire Mediterranean basin and iii) the use of one multi-scalar drought index (SPEI) particularly suitable for this region of the world (Vicente-Serrano et al., 2011, 2012b), iv) the assessment of the most sensitive areas, vegetation classes, seasons and time scales more prone to the negative effects on vegetation.

A cluster analysis performed using the standardized anomalies of stNDVI from GIMMS dataset allowed the identification of six main climate/vegetation classes based on the 
seasonal differences in the NDVI values, named as Desertic (D), Mediterranean Dry (MD), Mediterranean Oceanic (MO), Temperate Dry (TD), Temperate Oceanic (TO) and Temperate Continental (TC) vegetation classes. Results show a clear prevalence of the vegetation with the maximum of vegetation greenness in spring over the Southern Mediterranean countries and with a maximum in summer spread over the Northern part of the basin. While the wettest areas of western Europe allow higher vegetation activity throughout the entire year (Temperate Oceanic vegetation) or with a peak of NDVI in summer (Mediterranean Oceanic cluster), drier areas of the Eastern Europe present low vegetation activity, a typical feature in Temperate Dry and Mediterranean Dry clusters.

With the aim to identify regions and seasons most affected by climatic droughts, correlation maps between fields of monthly stNDVI and SPEI were obtained considering time scales ranging between 1 and 24 months. The area highly controlled by drought, as identified through the highest correlation values, shows large spatial and seasonal variability, with a maximum in August and a minimum in February. In August the area affected by drought is spread over the majority of the Mediterranean during August including north-western Iberia, France, north of Italy and west and north of Black Sea, whereas in February it is mainly confined to the west part of Mediterranean Basin (with exception for parts of Morocco), namely northern Africa and Iberia. On the other hand, during November the eastern part of the Mediterranean is particularly controlled by drought, namely the sectors located north and west of the Black sea. During February half of this area corresponds to the time scale of 6 months, while in November the time scale of 3 months represents around $40 \%$ of the selected grid points. Our results show that over Iberia and the eastern sector close to the Black sea, the shorter (longer) time scales are associated with the drier (wetter) clusters. These results are consistent with two of the three main clusters presented in Iberia: Mediterranean Oceanic and Dry vegetation clusters and with the corresponding main land cover types over this region: 
rainfed crops and sparse vegetation accordingly with GlobCover classification (see Figure 1). During May, the shorter time scale coincides mainly with the Mediterranean Dry cluster that includes vegetation stressed by low precipitation values and higher temperatures that lead to more sparse and less green vegetation, which also matches with the semi-arid region and could be associated with the vegetation classified as sparse vegetation and shrubs by GlobCover. The timescales of 6 and 12 months observed during May, correspond to the cluster of Mediterranean vegetation and could be associated with cropland (rainfed and mosaic). These results agree with those obtained by Vicente Serrano (2007) for Iberia who showed that for the influence of drought on vegetation for the semi-arid region of Ebro region, in Spain, varies along the year and is, in general, higher during spring and summer. The author showed that over pastures and cropland the 12 month time scale presents the higher correlation between Vegetation Condition Index (VCI) and SPI, indicating that vegetation activity is driven by the precipitation accumulated over the previous 12 months. On the other hand, in the semi-arid regions the sparse vegetation responds quickly to spatiotemporal changes in soil-moisture (Bonifacio et al., 1993; Vicente-Serrano, 2007; Vicente Serrano et al, 2013). Another interesting feature related to different time-scales dependence is the dipole observed west of the Black Sea during November. This region presents an area corresponding to the time-scale of 12 months in the center of the area contrasting with a large eastern area corresponding to the time-scale of 3 months. This dipole pattern split is related with the distribution of the Mediterranean Oceanic (mostly crops in Figure 1) and Temperate Dry (mostly forests in Figure 1) clusters. On the other hand this region presents a complex hydrology connected with long memory processes associated with snow dynamics and reinfiltration of water should also be taken in account). Consequently, in both regions, i.e. Iberia and the eastern sector close to the Black sea, the shorter (larger) time scales are associated with the drier (wetter) clusters and with sparse and denser/greener vegetation. These results 
are also in good agreement with the previous ones obtained for Iberia (Vicente-Serrano 2007) but equally for other regions, such as central U.S. (Quiring and Ganesh, 2010).

Understanding the time scales at which vegetation is driven by drought, as represented by the maximum correlation values between stNDVI and SPEI is extremely useful for resources management and mitigation measures. The highest control is obtained in February for the time scale of 3 months and in May for 6 and 12 months, over western Morocco, Tunisia, and some regions of Iberia. Similar results were previously obtained using SPI over croplands during the period of higher vegetation activity (Vicente-Serrano, 2007; Quiring and and Ganesh, 2010). While in February and May the largest correlation values are obtained essentially over Mediterranean Dry and Desertic Clusters, the lowest values are observed for the Temperate Oceanic and Mediterranean Oceanic clusters. This result is in accordance with the findings of Vicente-Serrano and co-authors (2013) who showed, at the global scale, that the dry biomes shows the stronger influence of drought on vegetation.

Nevertheless the influence of drought on vegetation depends also of the vegetation communities and seasons. Over Mediterranean Dry and Temperate Dry clusters the control of drought occurs at short time scales ( 6 and 3 months) for wet and cold season and at 9 and 12 months during the warmer and drier seasons. Several authors have pointed that the impact of droughts on vegetation activity is more evident in the most arid vegetation biomes that react quickly to water stress (Bonifacio et al, 1993, Vicente-Serrano, 2007, Quiring and Ganesh, 2010, Vicente-Serrano et al., 2013). On the other hand, vegetation dynamics during winter in Mediterranean Oceanic and Temperate Dry clusters is essentially constrained by low temperature (Gouveia et al., 2008). In that season vegetation tends to respond to drought episodes at longer time scales achieving the time scales of 18 and 24 months. The vegetation in sub-humid and semi-arid regions is adapted to tolerate regularly periods of water stress and 
has physiological mechanisms to resist to long periods of water scarcity (Vicente-Serrano et al., 2013).

This behavior is better understood if we analyze how climate variability explains the drought control on vegetation, as obtained by means of water balance. In this context, the strongest control is obtained during February and May for drier clusters in areas with low WB values (although positive in February and negative in May). In February this high control corresponds to shorter time scales. Accordingly the wet and cold seasons present low WB values that implies shorter time scales over dry cluster, whereas high WB values implies longer time scales over Mediterranean Oceanic and Temperate Oceanic clusters. Our results indicate a tendency for a change of the slope representing the dependence of the correlation values with WB; the dependence is negative for cold and wet seasons and tends to be positive for hot and dry seasons (although through non-significant regression adjustment in these cases). This feature highlights the different role played by WB along the year over the Mediterranean basin, becoming a strong limiting factor during the dry and hot seasons.

Our results have highlighted the important role of climate variability on the influence of droughts on vegetation dynamics. However other important factors should be taken into account for this response, such as land use/ land cover changes, soil proprieties, topography and land management policies (Quiring and Ganesh, 2010). In this context the Mediterranean basin presents high heterogeneity in the previous aspects, due the above mentioned natural factors but also to a wide range of distinct national land management policies. Several works have analyzed the behavior of drought events over the region during the last century (e.g. van Schrier et al. 2006; Sousa et al., 2011). A significant increase in frequency of drought events in the Mediterranean basin has been reported and incorporating a clear anthropogenic component (Hoerling et al., 2012; Trigo et al., 2013), being also compatible with all future 
scenarios of climate change. Besides changes on climate related variables other key factors such as land degradation and desertification becomes crucial to assess and monitor droughts with the aim of mitigating the environmental costs of the expected climatic changes. The occurrence of most affected areas over regions presenting low water balance values highlights the strong dependence of vegetation with WB. Furthermore, this conclusion is reinforced by the strong control of drought on vegetation activity observed for Desertic and Mediterranean Dry clusters located over areas with higher absolute values of WB. The projected increase in frequency of drought episodes emphasize the need for an early warning drought system covering the entire Mediterranean basin. However, our results highlight that this requirement is dependent of vegetation communities, season of the year and relative location of the regional sector considered (e.g. east-west). In this context we are confident that our results will provide a useful tool for drought management plans and play a relevant role in mitigating the impact of such episodes.

\section{Acknowledgements}

This work was partially supported by national funds through FCT (Fundação para a Ciência e a Tecnologia, Portugal) under project QSECA (PTDC/AAGGLO/4155/2012): Ricardo Trigo was supported by project LTER (LTER/BIA-BEC/0048/2009). Sergio M. Vicente-Serrano and Santiago Beguería were supported by project CGL2014-52135-C03-01 and Red de variabilidad y cambio climático RECLIM (CGL2014-517221-REDT) financed by the Spanish Commission of Science and Technology and FEDER. 


\section{References}

Alados, C.L., Puigdefábregas, J., Martínez-Fernández, J.: Ecological and socio-economical thresholds of land and plant-community degradation in semi-arid Mediterranean areas of southeastern Spain. Journal of Arid Environments 75, 1368-1376, 2011.

Amraoui M., Liberato M. L. R., Calado T. M., DaCamara C. C., Pinto-Coelho L., Trigo R. M., Gouveia C. M.: Fire activity over Mediterranean Europe based on information from Meteosat-8. Forest Ecology and Management, 294, 62-75, 2013

Austin R.B., Cantero-Martıínez C., Arrúe J.L., Playán E., and Cano-Marcellán P.: Yieldrainfall relationships in cereal cropping systems in the Ebro river valley of Spain, Eur. J. Agron. 8, 239-, 1998.

Baret, F., and Guyot G.: Potentials and limits of vegetation indices for LAI and APAR assessment, Remote Sensing of Environment, 35: 161-173,1991.

Barriopedro D., Fisher E., Luterbacher J., Trigo R.M., García-Herrera R.: The hot summer of 2010: redrawing the temperature record map of Europe. Science, Vol. 322, 220-224, 2011. doi: $10.1126 /$ science. 1201224

Bastos A., Gouveia C.M., Trigo R.M. and Running S.W.: Analysing the spatio-temporal impacts of the 2003 and 2010 extreme heatwaves on plant productivity in Europe, Biogeosciences 11: 3421-3435. DOI: 10.5194/bg-11-3421-2014.

Beguería S., Vicente-Serrano S.M. and Angulo M.: A multi-scalar global drought data set: the SPEIbase: A new gridded product for the analysis of drought variability and impacts. Bulletin of the American Meteorological Society 91, 1351-1354, 2010.

Beguería S., Vicente-Serrano S.M., Reig F., Latorre B.: Standardized precipitation evapotranspiration index (SPEI) revisited: parameter fitting, evapotranspiration models, tools, datasets and drought monitoring. International Journal of Climatology 34 (10): 3001 3023, 2014.

Bonifacio R., Dugdale G., and Milford J. R.: Sahelian rangeland production in relation to rainfall estimates from Meteosat, Int. J. Remote Sensing 14, 2695-2711.1993.

Braun-Blanquet J. and de Bolos O.: Datos sobre las comunidades terofiticas de las llanuras del Ebro medio. SIGMA communication no. 423. Collectanea Botanica 4: 235-242, 1954.

Camarero J.J., Manzanedo R.D., Sanchez-Salguero R. and Navarro-Cerrillo R.M.: Growth response to climate and drought change along an aridity gradient in the southernmost Pinus 
nigra relict forests. Annals of Forest Science 70 (8) 769, 2013. DOI: 10.1007/s13595-0130321-9

Carlson T.N. and Ripley D.A.: On the relation between NDVI, fractional vegetation cover, and leaf area index, Remote Sens. Environ., 62, 241-252, 1997.

Cihlar J.L. St-Laurent and Dyer J.A.: Relation between the normalized vegetation index and ecological variables. Remote Sensing of Environment 35: 279-298,1991.

Ciais P., Reichstein M., Viovy N., Granier A., Ogee J., Allard V., Aubinet M., Buchmann N., Bernhofer C., Carrara A., Chevallier F., De Noblet N., Friend A. D., Friedlingstein P., Grunwald T., Heinesch B., Keronen P., Knohl A., Krinner G., Loustau D., Manca G., Matteucci G., Miglietta F., Ourcival J.M., Papale D., Pilegaard K., Rambal S., Seufert G., Soussana J. F., Sanz M. J., Schulze E. D., Vesala,T., and Valentini R.: Europe-wide reduction in primary productivity caused by the heat and drought in 2003, Nature, 437, 529-533, 2005. doi: 10.1038/nature03972.

Coret L., Maisongrande P., Boone, A., Lobo A., Dedieu G., and Gouaux P.: Assessing the impacts of the 2003 hot and dry spell with SPOT HRVIR images time series over southwestern France, Int. J. Remote Sens., 26, 2461-2469, 2005. doi: $10.1080 / 01431160500057236$.

Diallo O., Diouf A., Hannan N.P., Ndiaye A., and Prevost Y.: AVHRR monitoring of savanna primary production in Senegal, West Africa: 1987-1988. International Journal of Remote Sensing 12(6): 1259-1279, 1991.

Dorman M., Svoray T., Perevolotsky A., Sarris, D.: Forest performance during two consecutive drought periods: Diverging long-term trends and short-term responses along a climatic gradient: Forest Ecology and Management 310, pp. 1-9, 2013

Ezzine H., Bouziane A., Ouazar D.: Seasonal comparisons of meteorological and agricultural droughtindices in Morocco using open short time-series data. International Journal of Applied Earth Observation and Geoinformation 26 (1), pp. 36-48, 2014.

Gao X.J., and Giorgi F: Increased aridity in the Mediterranean region under greenhouse gas forcing estimated from high resolution regional climate projections. Global and Planetary Change, 62,195-209, 2008.

García-Herrera R., Díaz J., Trigo R.M., Luterbacher, J., and Fischer, E.M.: A review of the European summer heat wave of 2003, Cr. Rev. Environ. Sci. Technol., 40, 267-306, 2010. doi:10.1080/10643380802238137. 
Giorgi, F.: Climate change hot-spots, Geophys. Res. Lett., 33, L08707, 2006, doi:10.1029/2006GL025734.

Giorgi F., Lionello P.; Climate change projections for the Mediterranean region. Global and Planetary Change, 63 (2-3): 90-104, 2008.

Gillies R.R., Carlson T.N., Cui J., Kustas W.P., Humes K.S.: A verification of the 'triangle' method for obtaining surface soil water content and energy fluxes from remote measurements of the Normalized Difference Vegetation index (NDVI) and surface radiant temperature. International Journal of Remote Sensing, 18, 3145-3166, 1997.

Goetz S.J., Fiske G.J., Bunn A.G.: Using satellite time-series data sets to analyze fire disturbance and forest recovery across Canada. Remote Sensing of of Environment 101 (3), 352-365, 2006.

Gouveia C., Trigo R.M., DaCamara C.C., Libonati R., Pereira J.M.C.: The North Temperate Oceanic Oscillation and European vegetation dynamics". International Journal of Climatology, 28, 1835-1847, 2008, DOI: 10.1002/joc.1682

Gouveia C., Trigo R.M, DaCamara C.C.: Drought and Vegetation Stress Monitoring in Portugal using Satellite Data, Natural Hazards and Earth System Sciences, 9, 185-195, 2009.

Gouveia C.M., Bastos A., Trigo R.M., DaCamara C.C.; Drought impacts on vegetation in the pre and post-fire events over Iberian Peninsula, Natural Hazards and Earth System Sciences, 12, 3123-3137, 2012.

Gurgel H. C., Ferreira N.J.: Annual and interannual variability of NDVI in Brazil and its connections with climate. International Journal of Remote Sensing, v.24, n. 18, p. 35953609, 2003.

Gutman G.G.: Vegetation indices from AVHRR: An update and future prospects. Remote Sensing of Environment 35:121-136, 1991.

Heumann B.W., Seaquist J.W., Eklundh L., Jonsson P.: AVHRR derived phonological change in the Sahel and Soudan, Africa, 1982-2005. Remote Sensing of Environment 108:385392, 2007.

Hoerling M., Eischeid J., Perlwitz J., Quan X., Zhang T., and Pegion, P.: On the Increased Frequency of Mediterranean Drought. J. Clim., 25, 2146-2161, 2012.

Holben B.N.: Characteristics of maximum-value composite images from temporal AVHRR data, Int. J. Remote Sens., 7, 1417- 1434, 1986. 
IPCC: Managing the Risks of Extreme Events and Disasters to Advance Climate Change Adaptation. A Special Report of Working Groups I and II of the Intergovernmental Panel on Climate Change [Field, C.B., V. Barros, T.F. Stocker, D. Qin, D.J. Dokken, K.L. Ebi, M.D. Mastrandrea, K.J. Mach, G.-K. Plattner, S.K. Allen, M. Tignor, and P.M. Midgley (eds.)]. Cambridge University Press, Cambridge, UK, and New York, NY, USA, 582 pp, 2012.

Jump A.S., Hunt J.M., Pen̈uelas J.: Rapid climate change-related growth decline at the southern range edge of Fagus sylvatica. Global Change Biology 12 (11), 2163-2174, 2006.

Knipling E.B.: Physical and physiological basis for the reflectance of visible and near-infrared radiation from vegetation. Remote Sensing of Environment 1, 155-159, 1970.

Kogan F.N.: Global drought watch from space. B. Amer. Meteor. Soc., 78, 621-636, 1997.

Limousin J.-M., Rambal S., Ourcival J.M., Rocheteau A., Joffre R., Rodriguez-Cortina R.: Long-term transpiration change with rainfall decline in a Mediterranean Quercus ilex forest. Global Change Biology 15 (9), pp. 2163-2175, 2009.

Lindner M., Maroschek M., Netherer S., Kremer A., Barbati A., Garcia-Gonzalo J., Seidl R., Delzon D., Corona P., Kolstro M., Lexer M.J., Marchetti M.: Climate change impacts, adaptive capacity, and vulnerability of European forest ecosystems. Forest Ecology and Management 259 (4), 698-709, 2010

Lionello P. (Editor): The Climate of the Mediterranean Region: From the Past to the Future, Elsevier, 502pp, 2012.

Lloret F., Lobo A., Estevan H., Maisongrande P., Vayreda J. and Terradas J.: Woody plant richness and ndvi response to drought events in catalonian (northeastern spain) forests. Ecology 88:2270-2279, 2007.

Lloyd-Hughes B. and Saunders M.A.: A drought climatology for Europe. Int. J. Climat., 22(13), 1571-1592, 2002.

Maherali H, DeLucia EH. 2001. Influence of climate-driven shifts in biomass allocation on water transport and storage in ponderosa pine. Oecologia 129: 481-491.

Martínez-Villalta J., López B.C., Adell N., Badiella L. and Ninyerola M.: Twentieth century increase of Scots pine radial growth in NE Spain shows strong climate interactions. Global change Biology 14: 2868-2881, 2008.

Myneni R.B., Hall F.G., Sellers P.J., and Marshak A.L.: The interpretation of spectral vegetation indices, IEEE Trans. Geosci. Remote Sens., 33, 481-486, 1995. 
Myneni R.B., Keeling C.D., Tucker C.J. et al.: Increased plant growth in the northern high latitudes from 1981 to 1991. Nature, 386, 698-701, 1997.

Nemani R.R., Keeling C.D., Hashimoto H. et al.: Climate-driven increases in global terrestrial net primary production from 1982 to 1999. Science, 300, 1560-1563, 2003.

Nicholson S.E., Tucker C.J. and Ba M.B.: Desertification, drought and surface vegetation: An example from the West African Sahel. B. Amer. Meteor. Soc., 79, 815-829, 1998.

Pasho E., Camarero J.J., De Luis M., Vicente-Serrano S.M.: Factors driving growth responses to drought in Mediterranean forests. Eur. J. For. Res .131:1797-1807, 2012.

Pausas J.G.: Changes in fire and climate in the eastern Iberian Peninsula (Mediterranean basin). Climatic Change 63, 337-350, 2004.

Paz-Kagan T., Panov N., Shachak M., Zaady E., Karnieli A.: Structural changes of desertified and managed shrubland landscapes in response to drought: Spectral, spatial and temporal analyses. Remote Sensing 6 (9), pp. 8134-8164, 2014

Pellizzaro G., Cesaraccio C., Duce P., Ventura A., Zara P.: Relationships between seasonal patterns of live fuel moisture and meteorological drought indices for Mediterranean shrubland species, International Journal of Wildland Fire 16 (2), pp. 232-241, 2007.

Peñuelas, J., Lloret F., Montoya R.: Severe drought effects on mediterranean woody flora in Spain Forest Science 47 (2), pp. 214-218, 2001.

Pickup G.: Desertification and climate change - The Australian perspective. Climate Research 11, 51-63, 1998.

Pinzon J.E., Tucker C.J.: A Non-Stationary 1981-2012 AVHRR NDVI3g Time Series. Remote Sens. 2014, 6, 6929-6960.

Puigdefábregas J., Mendizábal T.: Perspectives on desertification: western Mediterranean. Journal of Arid Environments 39, 209-224, 1998.

Quiring S.M. and Ganesh S.: Evaluating the utility of the Vegetation Condition Index (VCI) for monitoring meteorological drought in Texas. Agricultural and Forest Meteorology. 150: 330-339, 2010.

Rivas-Martínez, S., S. Rivas-Sáenz, and A. Penas. 2011. Worldwide bioclimatic classification system. Global Geobotany 1: 1-634.

Rodríguez-Puebla C., Ayuso S.M., Frías M.D., García-Casado L.A.: Effects of climate variation on winter cereal production in Spain, Climate Research 34 (3), pp. 223-232, 2007. 
Rouse J.W.: Monitoring the vernal advancement of retrogradation of natural vegetation. NASA/GSFC, Type III, Final Report, Greenbelt, MD, pp. 371, 1974.

Schillinger W.F., Schofstoll S.E., Alldredge J.R.: Available water and wheat grain yield relations in a Mediterranean climate, Field Crops Research 109 (1-3), pp. 45-49, 2008

van der Schrier G, Briffa K.R., Jones P.D. and Osborn T.J.: Summer moisture variability across Europe. Journal of Climate 19, 2818-2834, 2006. doi:10.1175/JCLI3734.1.

Sousa P., Trigo R.M., Aizpurua P., Nieto R., Gimeno L., Garcia-Herrera R.: Trends and extremes of drought indices throughout the 20th century in the Mediterranean. Natural Hazards and Earth System Sciences, 11, 33-51, doi: 10.5194/nhess-11-33-2011.

Trigo R.M., García-Herrera R., Díaz J., Trigo I.F., Valente M.A.: How exceptional was the early August 2003 heatwave in France? Geophysical Research Letters, 32, L10701, 2005. doi:10.1029/2005GL022410

Trigo R.M., Gouveia C., Barriopedro D.: The intense 2007-2009 drought in the Fertile Crescent: Impacts and associated atmospheric circulation, Agricultural and Forest Meteorology, 150, 1245-1257, 2010.

Trigo R.M., Añel J., Barriopedro D., García-Herrera R., Gimeno L., Nieto R., Castillo R., Allen M.R., Massey N.: The record Winter drought of 2011-12 in the Iberian Peninsula [in "Explaining Extreme Events of 2012 from a Climate Perspective". [Peterson, T. C., M. P. Hoerling, P.A. Stott and S. Herring, Eds.] Bulletin of the American Meteorological Society, 94 (9), S41-S45, 2013.

Tucker C.J., Vanpraet C., Boerwinkel E. and Gaston A.: Satellite remote sensing of total dry matter production in the Senegalese Sahel. Remote Sensing of Environment 13: 461-474, 1983.

Tucker C.J., Pinzon J.E., Brown M.E., Slayback D.A., Pak E.W., Mahoney R. et al. An extended AVHRR 8-km NDVI dataset compatible with MODIS and SPOT vegetation NDVI data. International Journal of Remote Sensing 2005, 26, 4485-4498.

Udelhoven T., Stellmes, M., del Barrio G., Hill J. Assessment of rainfall and NDVI anomalies in Spain (1989-1999) using distributed lag models. International Journal of Remote Sensing 30 (8), pp. 1961-1976, 2009.

Van der Schrier G., Briffa K.R., Jones P.D., and Osborn T. J.: Summer moisture variability across Europe. J. Climate, 19, 2818-2834, 2006.

Vicente Serrano S.M.: Evaluating the Impact of drought using Remote Sensing in a Mediterranean, semi-arid region. Natural Hazards, 40,173-208, 2007. 
Vicente-Serrano, S.M., López-Moreno, J.I., Drumond, A., Gimeno, L., Nieto, R., MoránTejeda, E., et al.: Effects of warming processes on droughts and water resources in the NW Iberian Peninsula (1930-2006). Climate Res. 48, 203-212, 2011. doi: 10.3354/cr01002

Vicente-Serrano S.M., Gouveia C., Camarero J.J., Beguería S., Trigo R.M., López-Moreno J.I., Azorín-Molina C., Pasho E., Lorenzo-Lacruz J., Revuelto J, Morán-Tejeda E., Sanchez-Lorenzo A.: Response of vegetation to drought time-scales across global land biomes. Proceedings of the National Academy of Sciences, 110:52-57, 2013, doi:10.1073/pnas.1207068110

Vicente-Serrano S.M., López-Moreno J.I., Beguería S., A multi-scalar drought index sensitive to global warming: The standardized precipitation evapotranspiration index - SPEI, Journal of Climate, 23, 1696-1718.2010.

Vicente-Serrano S.M., Zouber A., Lasanta T. and Pueyo Y.: Dryness is accelerating degradation of vulnerable shrublands in semiarid Mediterranean environments. Ecological Monographs, 82(4), 2012, pp. 407-428, 2012a.

Vicente-Serrano, S.M., Beguería S., Lorenzo-Lacruz J., Camarero J.J., López-Moreno J.I., Azorin-Molina C., Revuelto J., Morán-Tejeda E. and Sánchez-Lorenzo A.: Performance of drought indices for ecological, agricultural and hydrological applications. Earth Interactions 16, 1-27, 2012b.

Vicente-Serrano S.M., López-Moreno J.I., Beguería S., Lorenzo-Lacruz J., Sanchez-Lorenzo A., García-Ruiz J.M., Azorin-Molina C., Móran-Tejeda E., Revuelto J., Trigo R., Coelho F., Espejo F.: Evidence of increasing drought severity caused by temperature rise in southern Europe. Environmental Research Letters, 9, 044001, 2014. 
Table 1: Number of pixels presenting significant correlations for different time scales and months. The number of outliers (percentage) for each time scale and months (Figure 8) is in brackets.

\begin{tabular}{|c|c|c|c|c|c|c|c|}
\hline & $\mathbf{0 3}$ & $\mathbf{0 6}$ & $\mathbf{0 9}$ & $\mathbf{1 2}$ & $\mathbf{1 8}$ & $\mathbf{2 4}$ & Total \\
\hline Feb & 636 & 4808 & 1367 & 248 & 665 & 1186 & 8910 \\
& $(0.9 \%)$ & $(0 \%)$ & $(0 \%)$ & $(3.6 \%)$ & $(2.3 \%)$ & $(3.4 \%)$ & \\
\hline May & 5083 & 6433 & 4568 & 2093 & 1573 & 1613 & 21363 \\
& $(0.6 \%)$ & $(0 \%)$ & $(0 \%)$ & $(0 \%)$ & $(3.0 \%)$ & $(2.2 \%)$ & \\
\hline Aug & 11627 & 6559 & 7112 & 5611 & 4071 & 4927 & 39907 \\
& $(0.5 \%)$ & $(0 \%)$ & $(0 \%)$ & $(0.6 \%)$ & $(0.6 \%)$ & $(1.4 \%)$ & \\
\hline Nov & 5922 & 1392 & 690 & 2309 & 1923 & 1936 & 14172 \\
& $(1.2 \%)$ & $(2.1 \%)$ & $(0.7 \%)$ & $(1.0 \%)$ & $(1.90 \%)$ & $(1.9 \%)$ & \\
\hline
\end{tabular}


Table 2: As in Table 1 but respecting to different vegetation clusters.

\begin{tabular}{|c|c|c|c|c|c|c|}
\hline & TO & MO & MD & TC & TD & D \\
\hline Feb & 390 & 1770 & 3381 & 483 & 920 & 1831 \\
& $(3.8 \%)$ & $(1.1 \%)$ & $(0 \%)$ & $(4.6 \%)$ & $(1.7 \%)$ & $(0 \%)$ \\
\hline \multirow{2}{*}{ May } & 1193 & 5711 & 7679 & 1118 & 2072 & 3282 \\
& $(2.5 \%)$ & $(0.9 \%)$ & $(0 \%)$ & $(2.6 \%)$ & $(1.8 \%)$ & $(0 \%)$ \\
\hline \multirow{2}{*}{ Aug } & 7552 & 6510 & 6777 & 5327 & 11263 & 2153 \\
& $(0.4 \%)$ & $(0.7 \%)$ & $(0 \%)$ & $(1.2 \%)$ & $(0 \%)$ & $(0 \%)$ \\
\hline \multirow{2}{*}{ Nov } & 438 & 1597 & 2593 & 3172 & 5049 & 1151 \\
& $(0.4 \%)$ & $(0.8 \%)$ & $(0 \%)$ & $(0.6 \%)$ & $(0.9 \%)$ & $(0 \%)$ \\
\hline
\end{tabular}



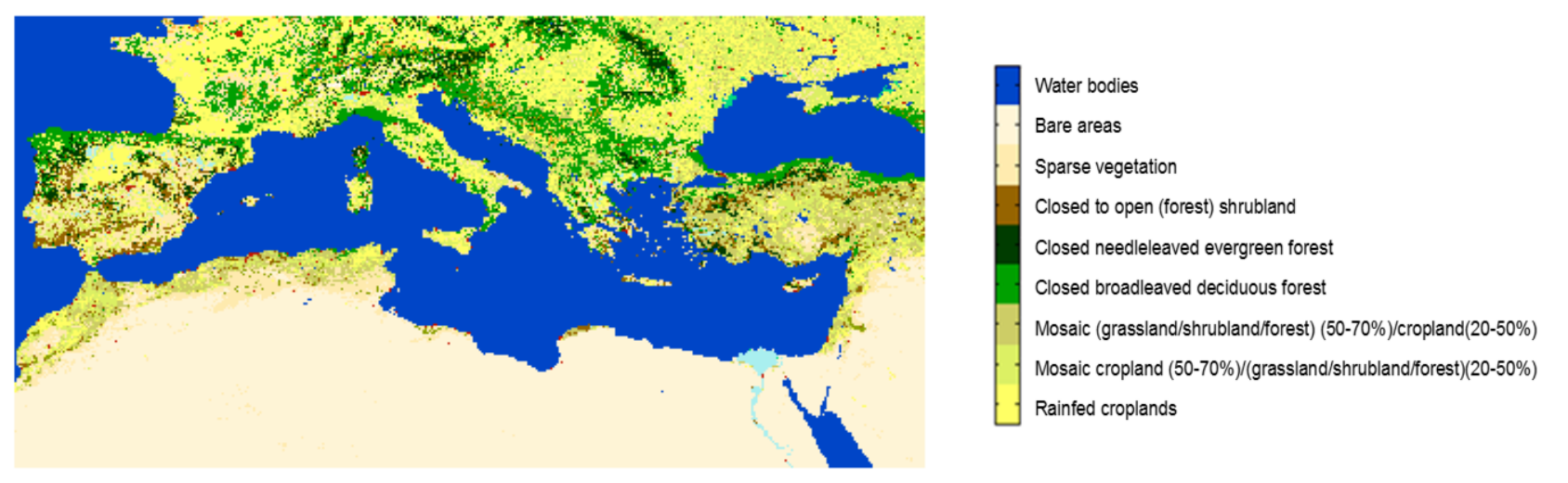

Figure 1. Globcover classification for mediterranean region. 

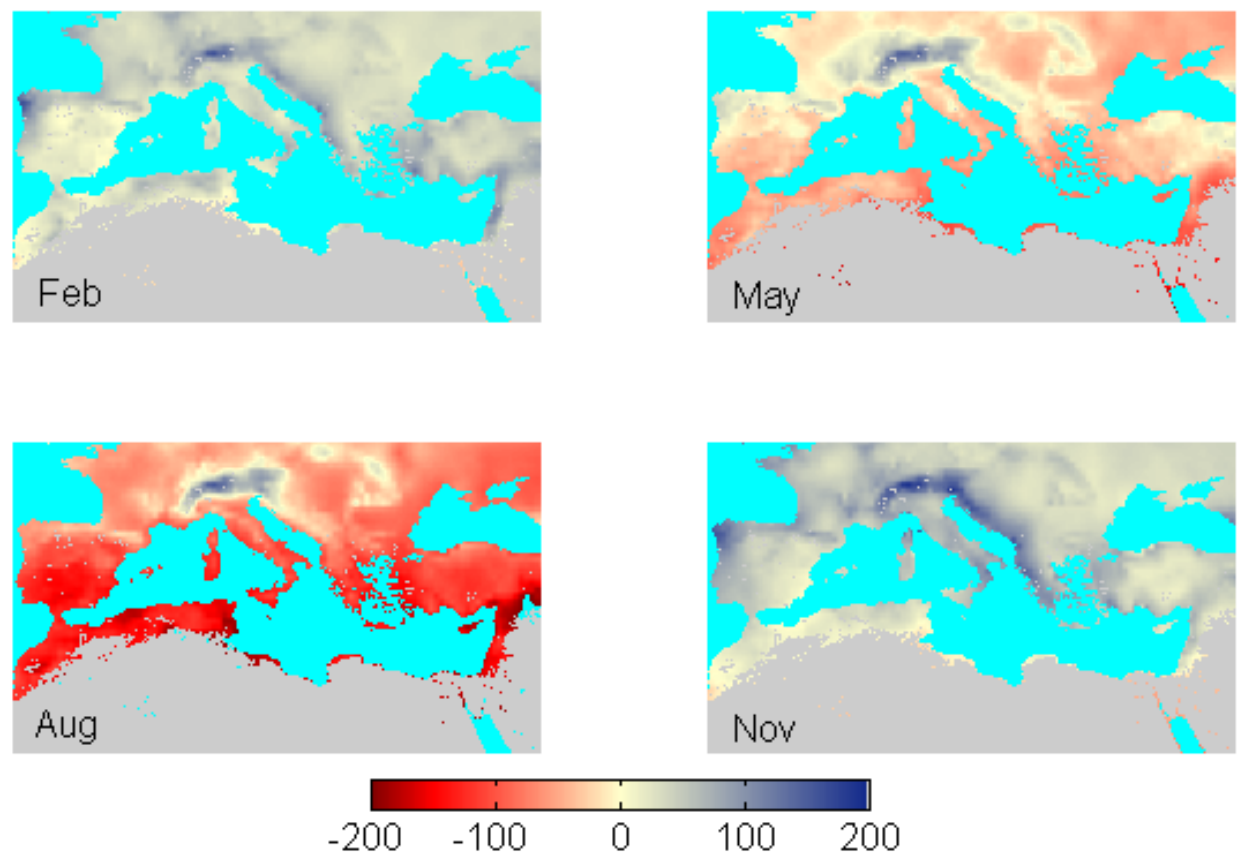

Figure 2. Spatial distribution of water balance (mm/month) for February, May, August and November. 

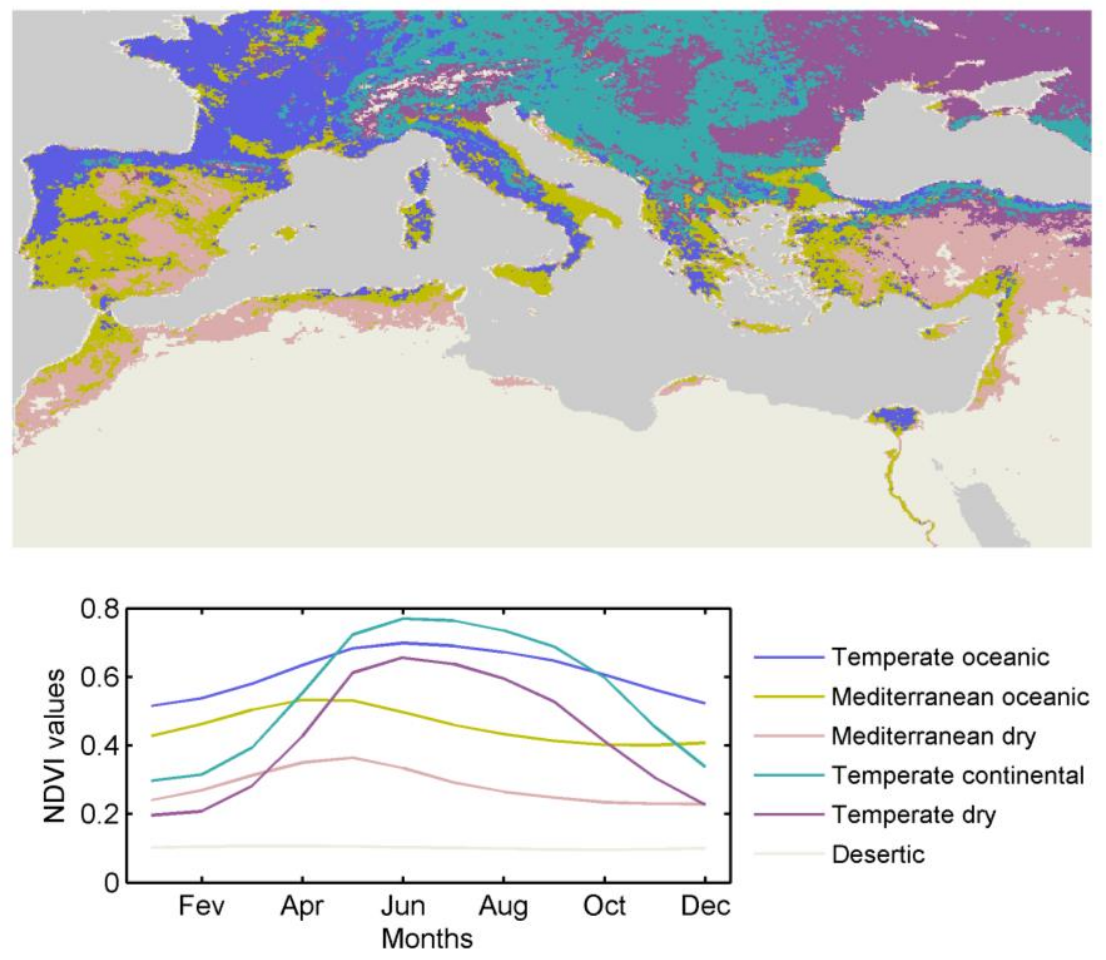

Figure 3. Spatial distribution of the six vegetation clusters of NDVI obtained with GIMMS dataset for the period 1982-2006 (top panel) and the annual cycles of monthly NDVI that characterize the centroids of the six identified vegetation clusters (bottom panel). 
Feb

03

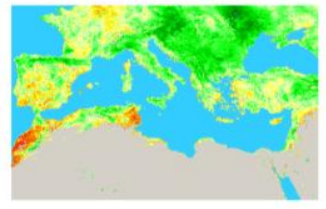

06

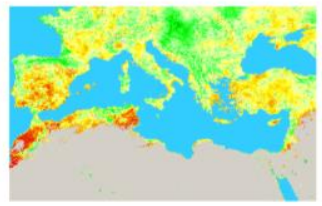

09

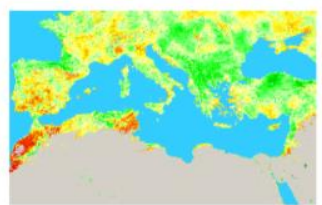

12

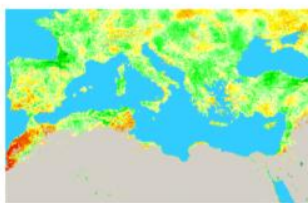

18

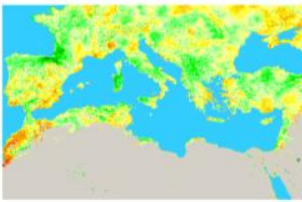

24

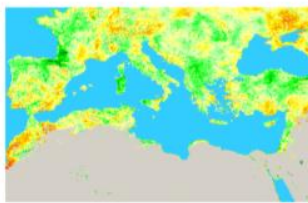

May
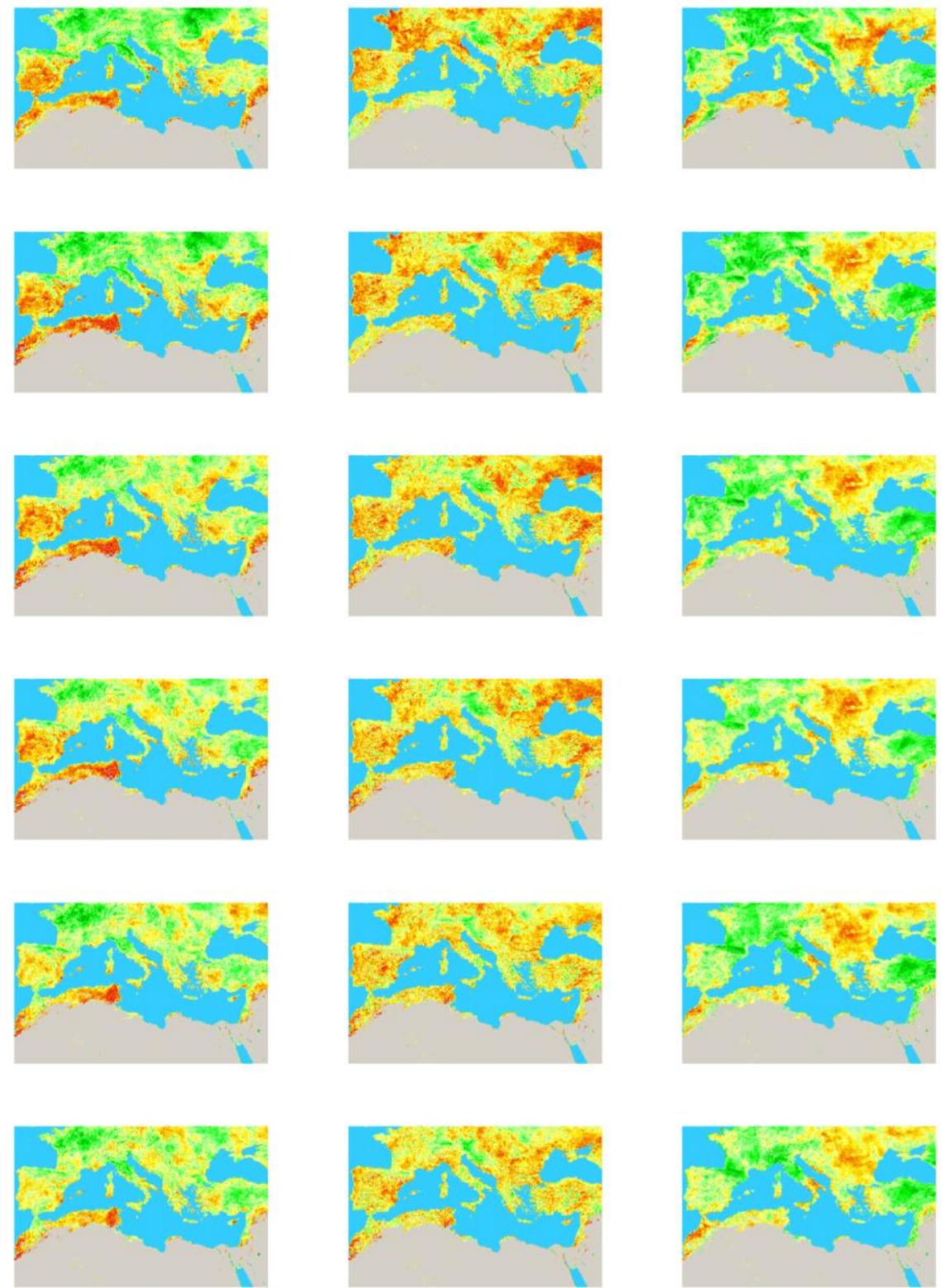

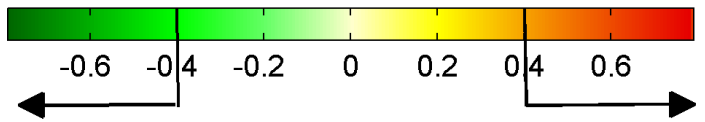

Figure 4. Spatial distribution of correlations between stNDVI and SPEI for February, May, August and November, using the temporal scales of 3, 6, 9, 12, 18 and 24 months. The Area without vegetation or with irrigated crops (accordingly with the GlobCover classification) was masked out and are represented in gray). The colour bar shows values of the Spearman's rank correlation statistic, and the two arrows indicate the ranges that are significant at $\mathrm{p}<0.05$. 

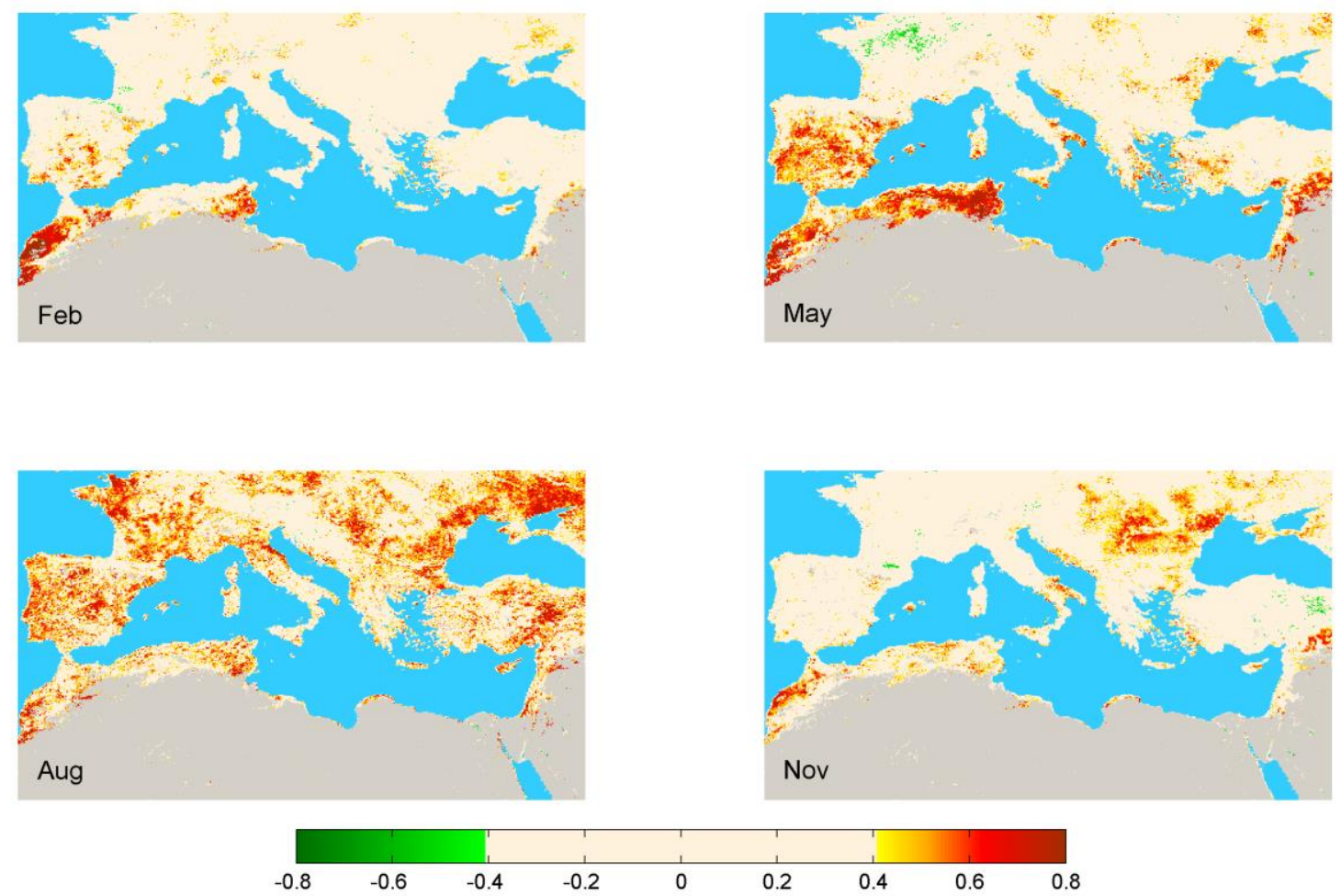

Figure 5. Spatial distribution of the maximum of the significant $(\mathrm{p}<0.05)$ grid point correlations between stNDVI and SPEI for the time scales of 3, 6, 9, 1218 and 24 months, during February (upper left panel), May (upper right panel), August (bottom left panel) and November (bottom right panel). 

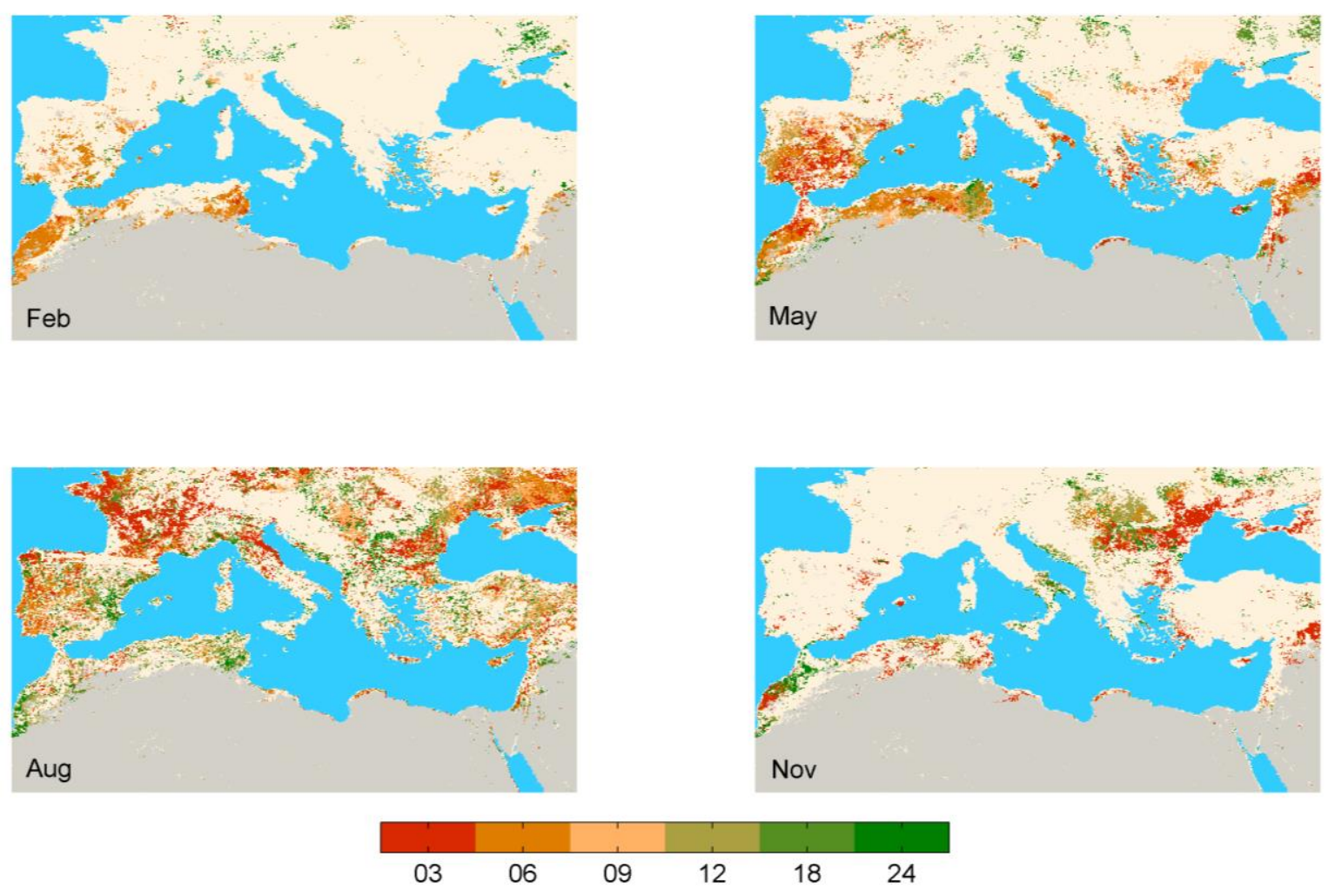

Figure 6. Time scale of the SPEI showing the maximum correlation with the stNDVI. Nonsignificant correlations were masked out and are represented in white. 

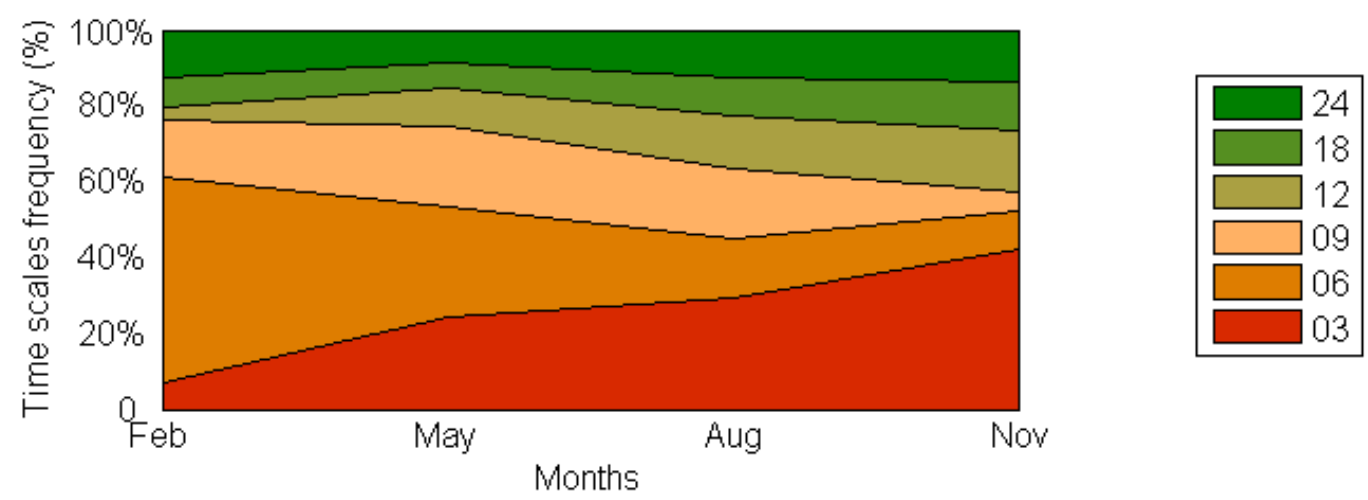

Figure 7. Relative proportions of the time-scales showing the maximum correlation in the areas with significant correlations between SPEI and stNDVI in February, May, August and November. 

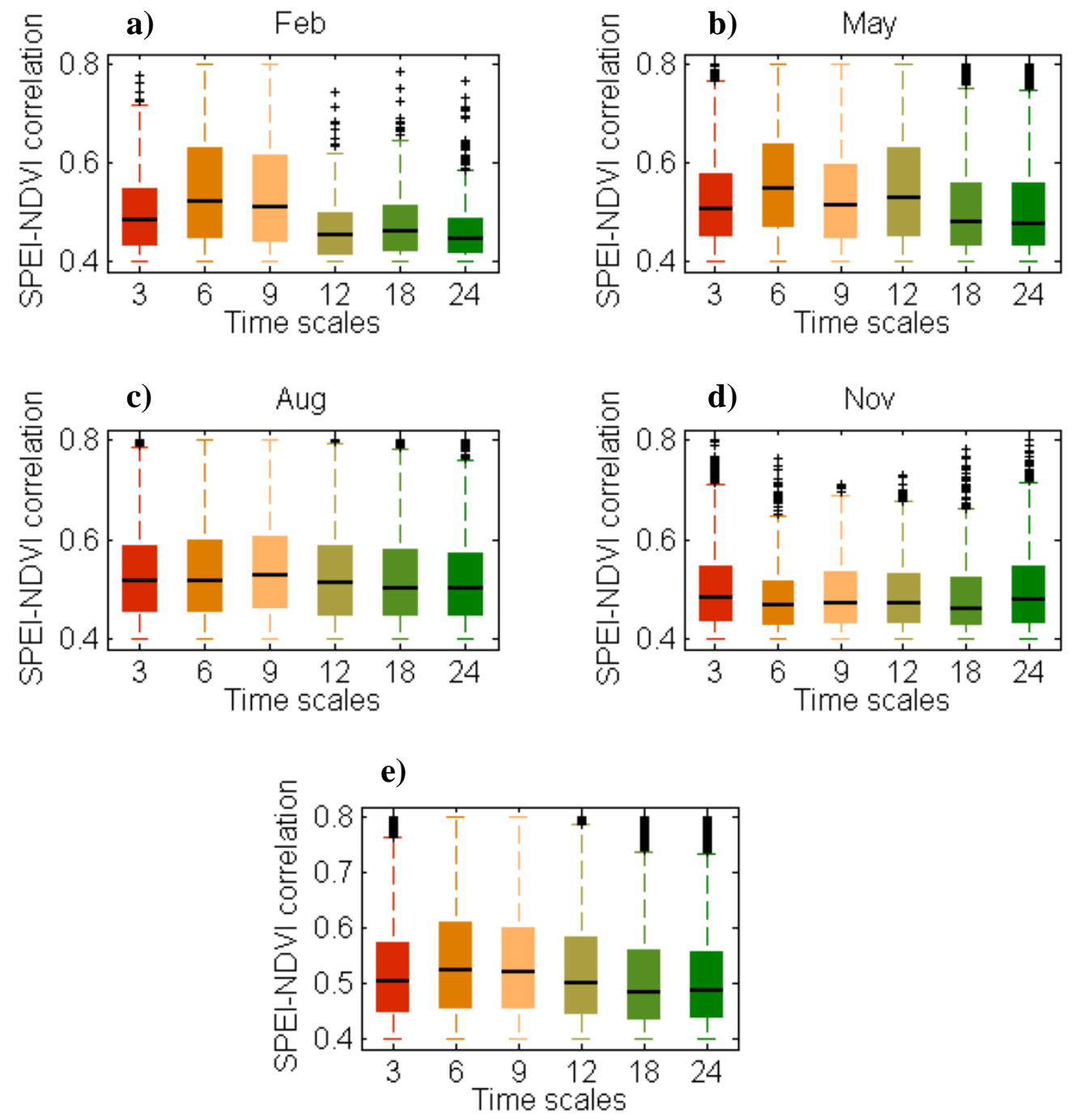

Figure 8. Boxplots of correlation values between stNDVI and SPEI for the area affected by drought (presenting significant positive correlation values) on a seasonal (a, b, c and d) and annual basis (e) corresponding to different time scales. The median for each time scale is represented by the bold black line in the boxes and the outliers are represented by the black sign + . 

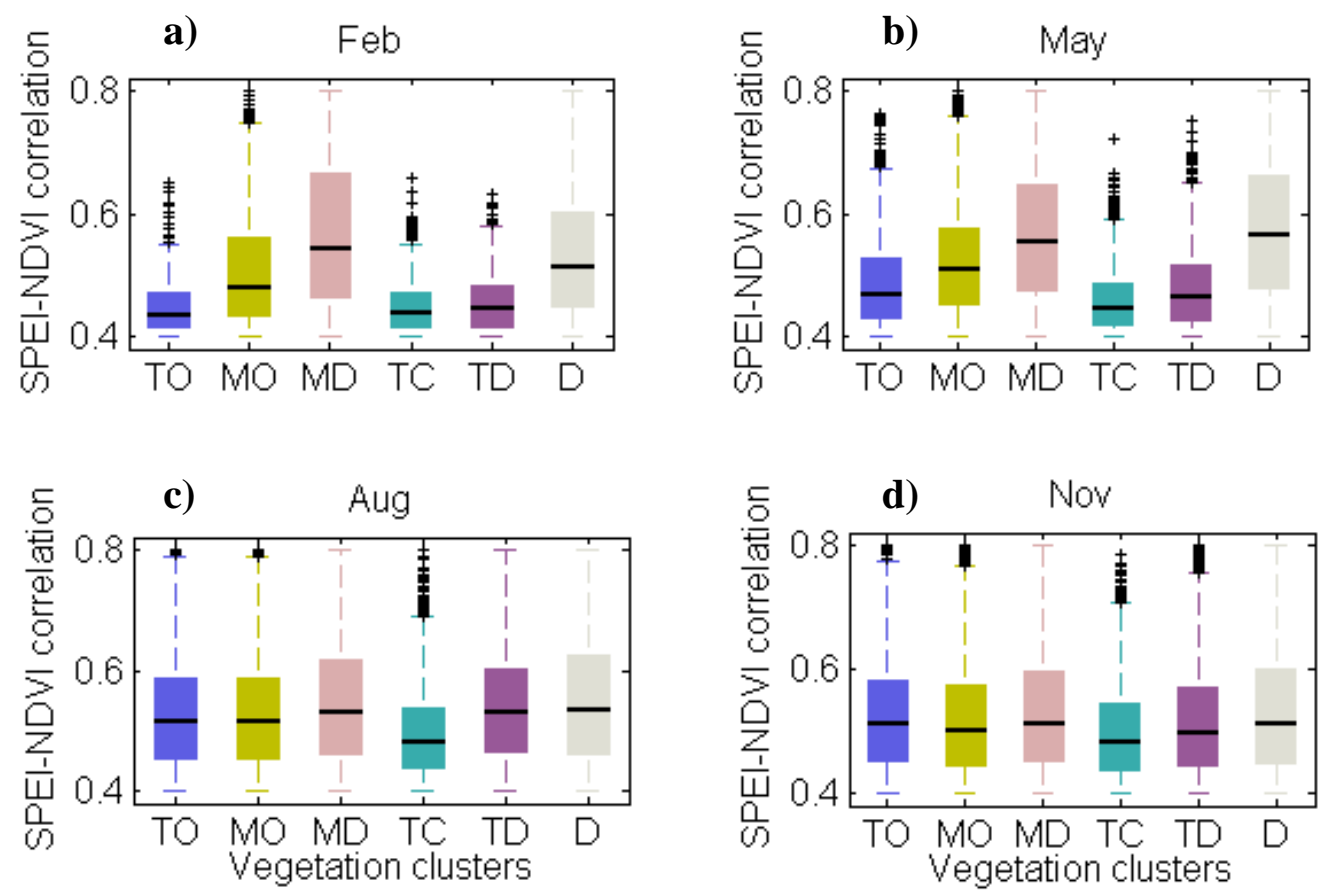

e)

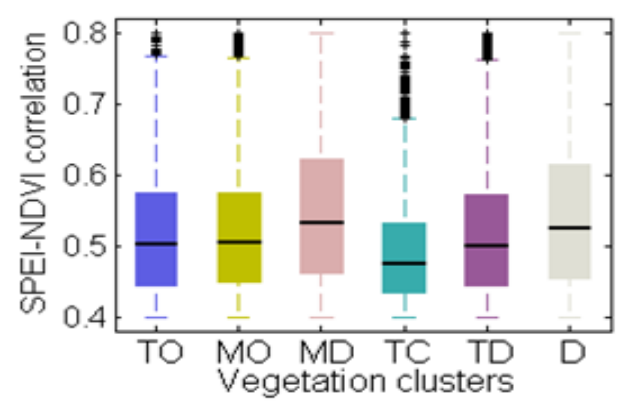

Figure 9. As in Figure 8 but respecting to different vegetation types. 

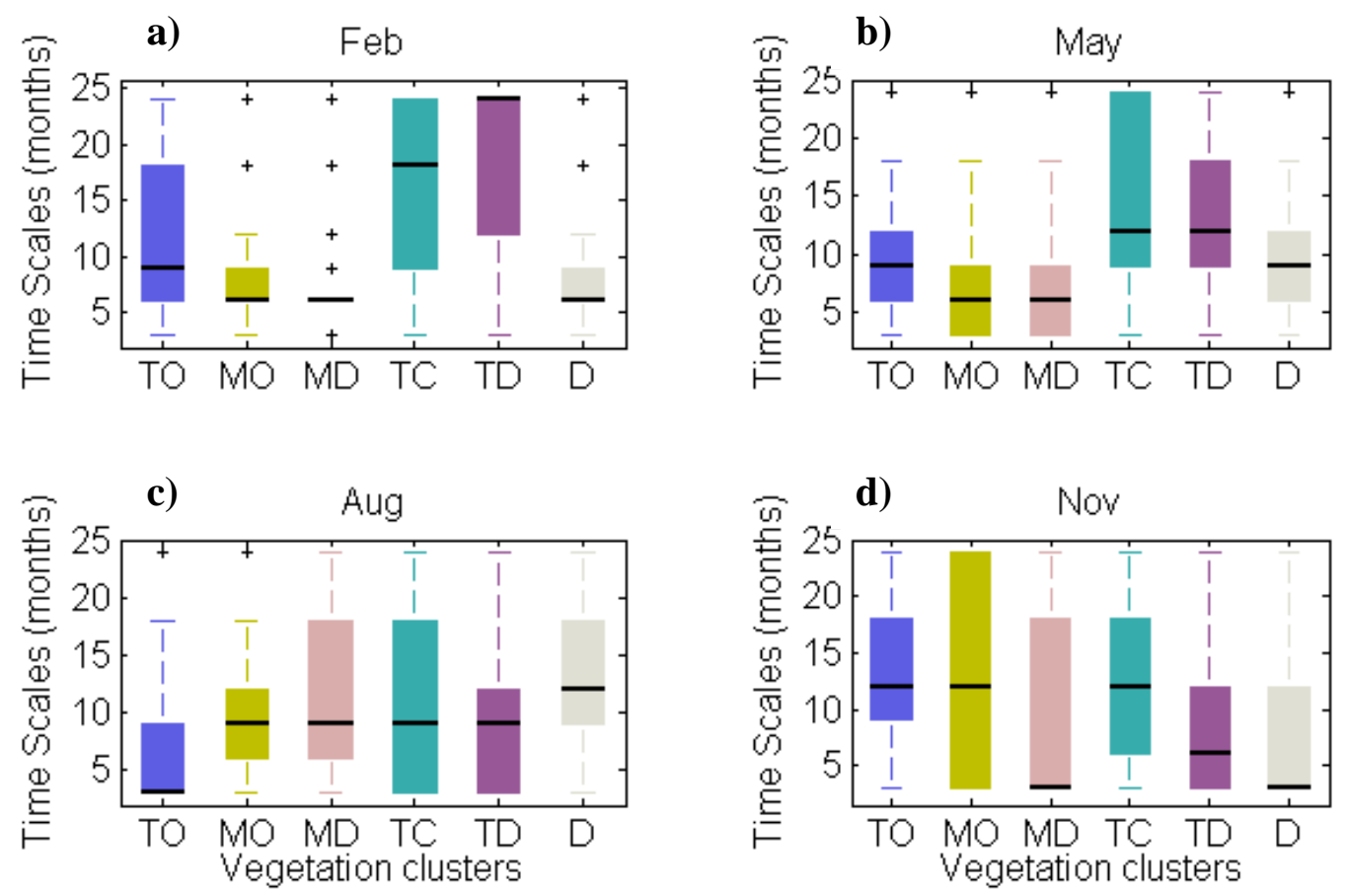

e)

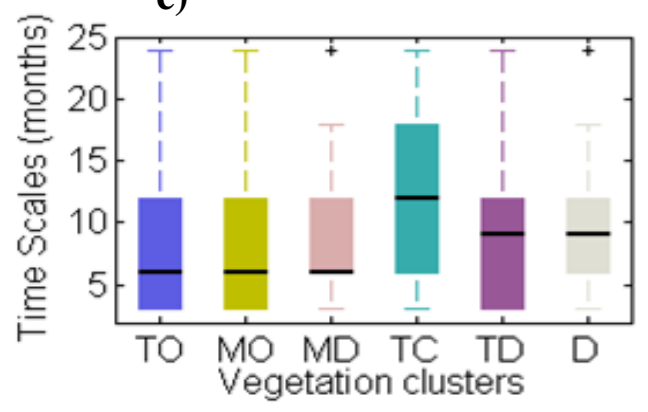

Figure 10. As in Figure 8 but for different time scales over different clusters. 
A)
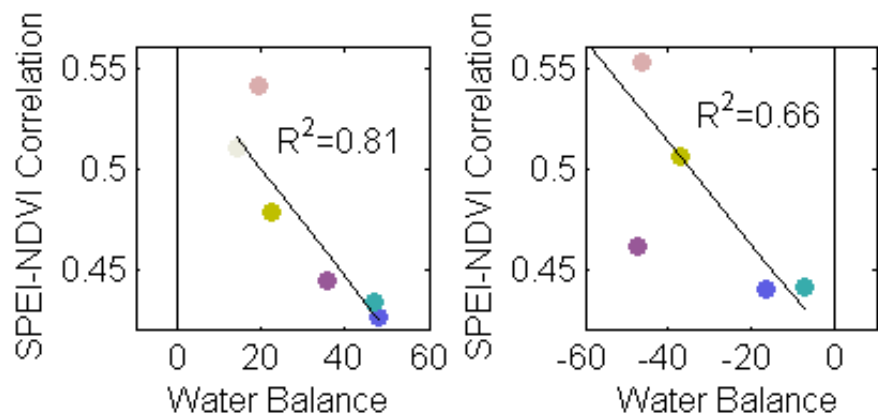

- TO
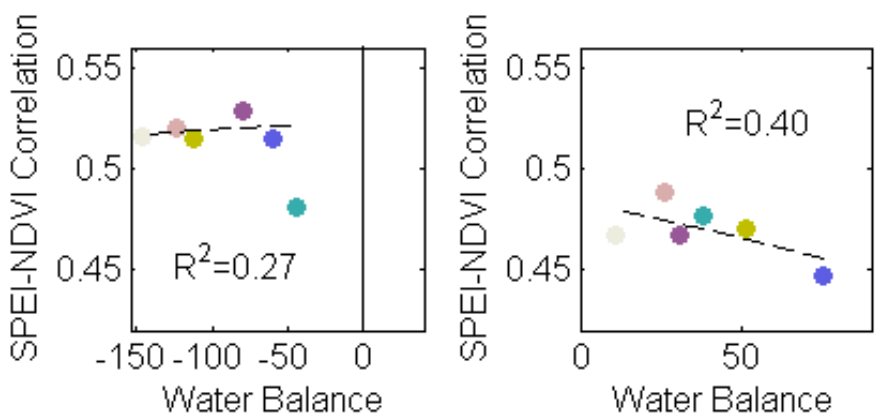

- MD

- TC

- TD

- D

B)
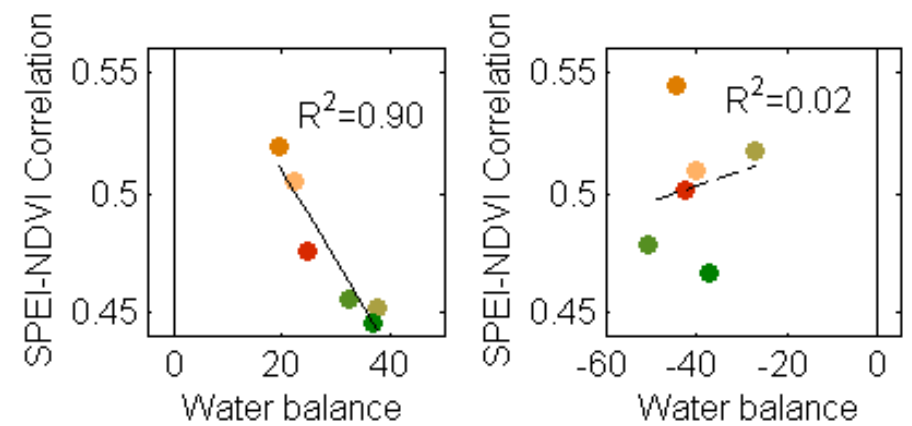

- SPEI03

- SPEI06

- SPEI09
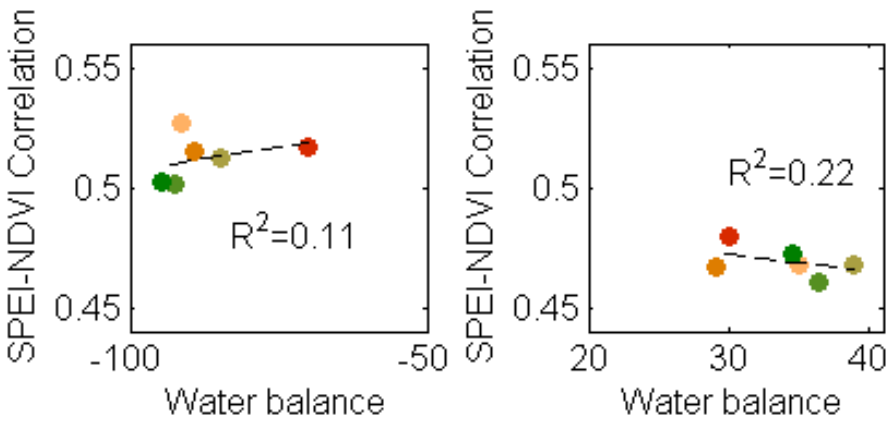

- SPEI12

- SPEI18

- SPEI24

Figure 11. Relationship between the average SPEI-stNDVI correlation and the average water balance during February, May, August and November for the a) different vegetation clusters and b) different time scales. 

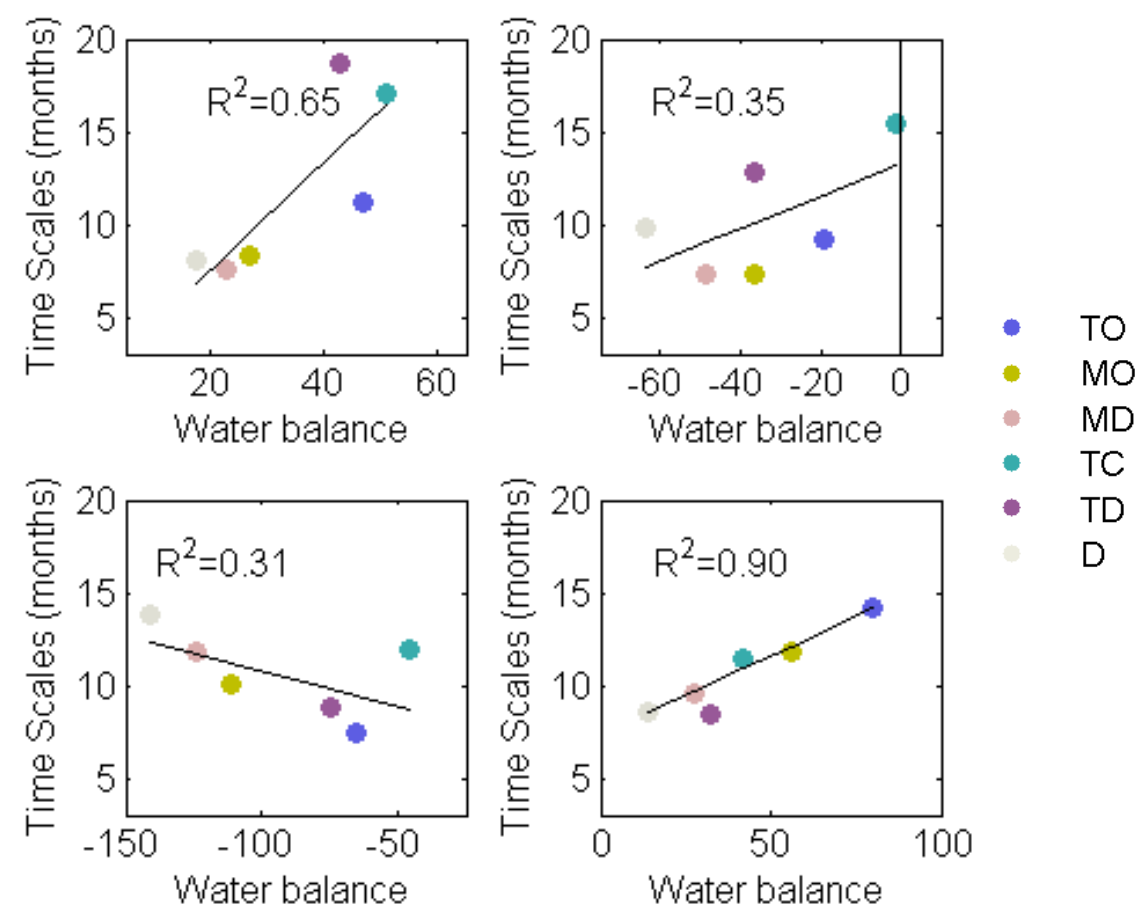

Figure 12. Relationship between the time scales and the averaged water balance during February, May, August and November for the different vegetation clusters 